\title{
Qualitative Evaluation of the Performance of Chemical Fume Hoods Located in the Laboratories of the University of Medical Sciences in 2017
}

\author{
Maryam Feiz Arefi ${ }^{1}$, Farshid Ghorbani Shahna ${ }^{2, *}$, Azam Karamimosafer ${ }^{1}$ \\ ${ }^{1}$ MSc in Occupational Health Engineering, Student Research Committee, Department of Occupational Health, Faculty of \\ Health, University of Medical Sciences, Hamadan, Iran \\ ${ }^{2}$ Associate Professor, Scientific Center of Excellence for Occupational Health, Health and Occupational Safety Research \\ Center, Department of Occupational Health, Faculty of Health, Hamadan University of Medical Sciences, Hamadan, Iran
}

* Corresponding Author: Farshid Ghorbani Shahna, Scientific Center of Excellence for Occupational Health, Health and Occupational Safety Research Center, Department of Occupational Health, Faculty of Health, Hamadan University of Medical Sciences, Hamadan, Iran.Email: fghorbani@umsha.ac.ir

Received: $18 / 12 / 2017$

Accepted: 26/04/2018

How to Cite this Article:

Feiz Arefi M, Ghorbani Shahna F, Karamimosafer A. Qualitative Evaluation of the Performance of Chemical Fume Hoods Located in the Laboratories of the University of Medical Sciences in 2017. J Occup Hyg Eng. 2018; 5(1): 1-7. DOI: 10.21859/johe-5.1.1

\begin{abstract}
Background and Objective: A variety of chemical and biological materials are used in the scientific and research laboratories of the universities of medical sciences. Various people, including the laboratory staff, students, and faculty members, are exposed to these materials; accordingly, various respiratory and dermatological symptoms may occur in these people. Regarding this, the aim of the present study was to evaluate the chemical fume hoods used in the laboratories of the medical universities.

Materials and Methods: This study was conducted on 43 chemical hoods of the laboratories of the universities of medical sciences. The technical specifications of the hoods and their compliance with the standards were investigated. The amount of hood suction was measured through air flow visualization and hood face velocity using a thermal anemometer. The data were analyzed in SPSS software, version 19.

Results: According to the results, $51.2 \%$ and $44.2 \%$ of the hoods had inappropriate conditions in terms of hardware and location, respectively. Maximum of face velocity was $96.16 \mathrm{ft} / \mathrm{min}$. The results showed that $50.2 \%$ of the hoods had a visible leakage. The mean face velocities were not suitable in any of the hoods when they were $100 \%$ and $50 \%$ open. These velocities were appropriate only when the hoods were $25 \%$ open.

Conclusion: Based on the findingss, the hardware and performance characteristics of most of the hoods were inappropriate. Furthermore, they had a low impact on the control of pollutants. Consequently, it is necessary to adapt to the changes and modifications of the hoods in accordance with the standards. An annual assessment of hood performance should also be applied in the hood maintenance program.
\end{abstract}

Keywords: Hood; Laboratory; Quality Assessment 
dot: $10.21859 /$ johe-5.1.1

\title{
ارزيابى كيفى عملكرد هودهاى شيميايى مستقر در آزمايشكاههاى دانشكاه علوم يزشكى در سال 149
}

\begin{abstract}
مريم فيض عارفى'، فرشيد قربانى شهنا؟،*، اعظم كرمى مسافر'
ا كارشناسى ارشد، مههندسى بهداشت حرفهاى، گروه بهداشت حرفهاى، كميته تحقيقات دانشجويى، همدان، ايران

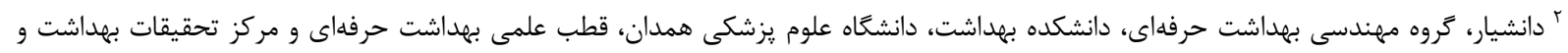
ايمنى شغلى، همدان، ايران

* نويسنده مسئول: فرشيد قربانى شهنا، كروه مهندسى بهداشت حرفهاى، دانشكده بهداشت، دانشكاه علوم يزشكى همدان، قطب علمى بهداشت حرفهاى

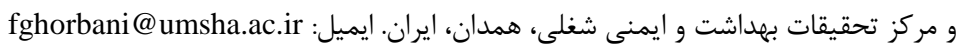

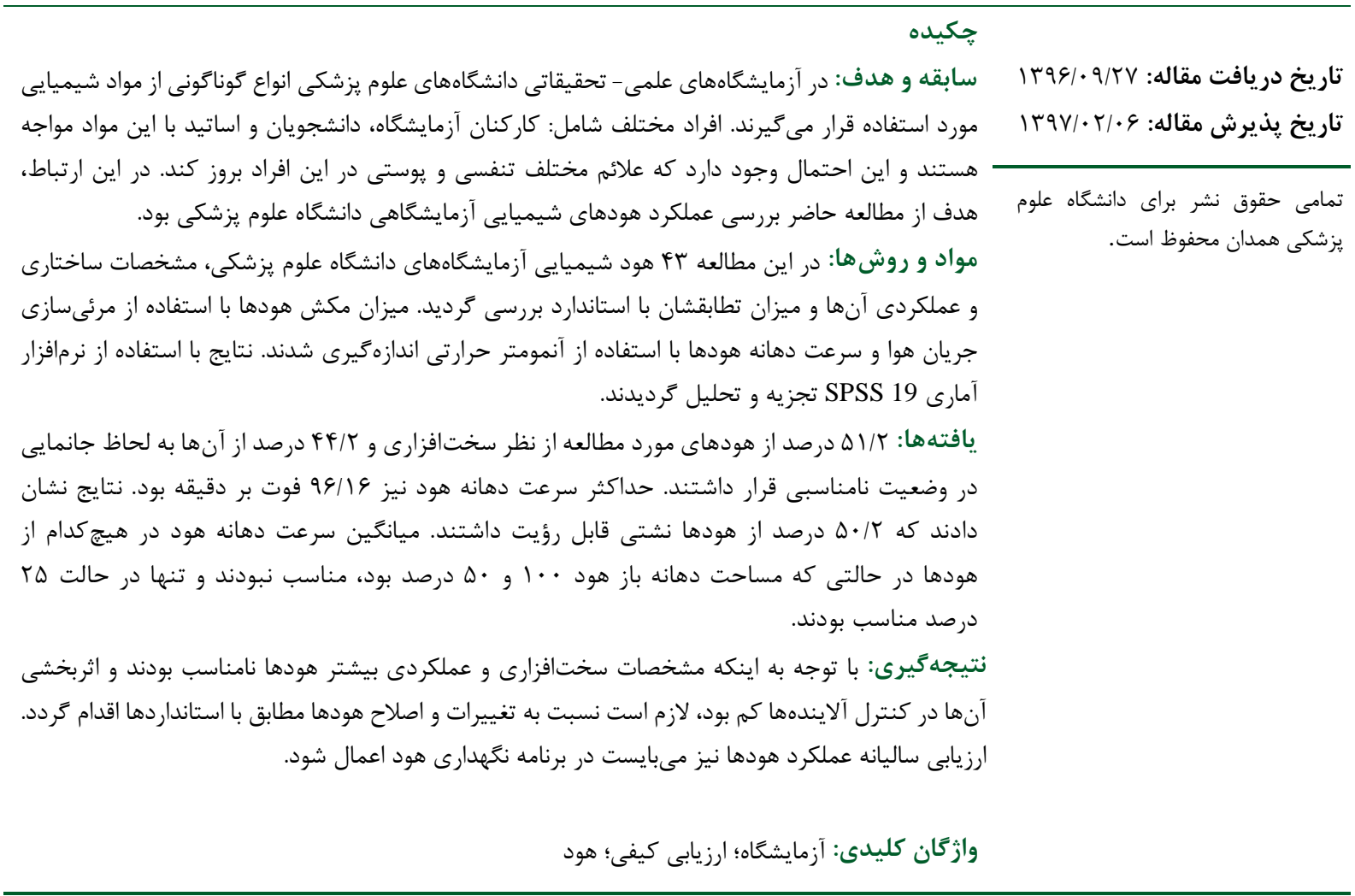

مقدمه

برخوردار هستند و سو درصد از مواجهلهاى دانشجويان و

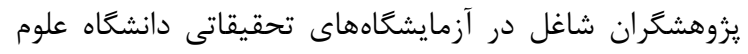

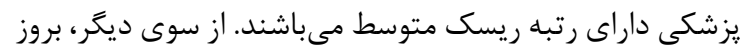

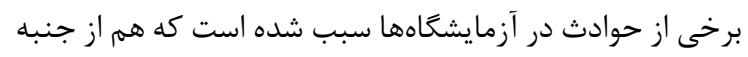

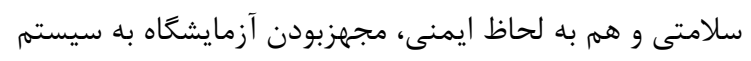

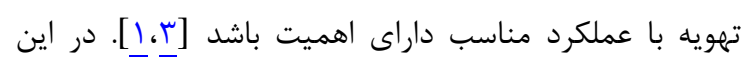

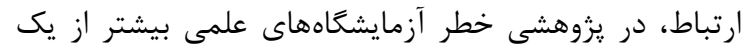

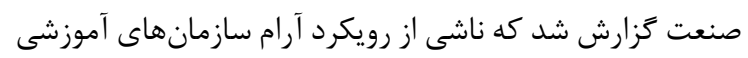

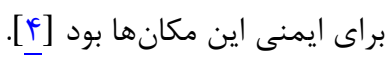

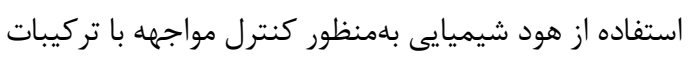

در آزمايشگاههاى علمى - تحقيقاتى انواع گَوناگونى از مواد

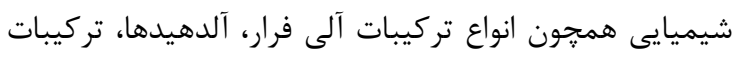
هالوزنه، الكلها و غيره مورد استفاده قرار ميى گئيرند. افراد مختلفى به دليل كار خود با اين مواد مواجه هستند و واين موردين

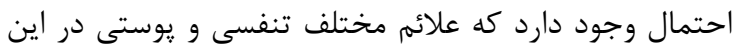

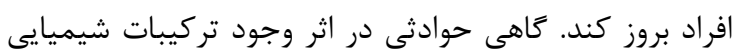

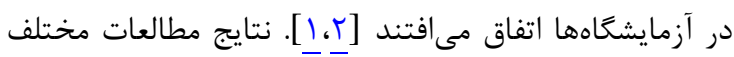

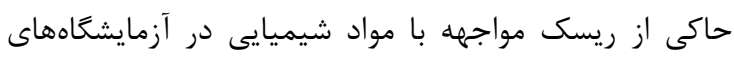

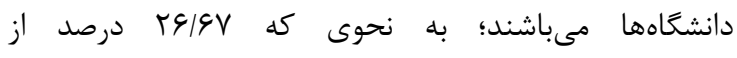

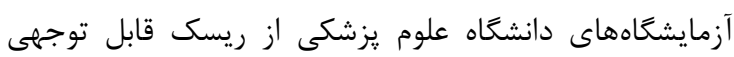


فضاها با يكديگر و بستهبودن فضا، در صورت مناسبنبودن

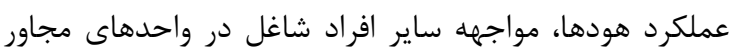

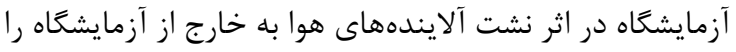

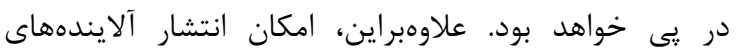

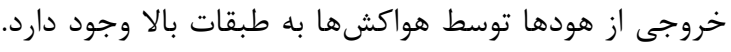

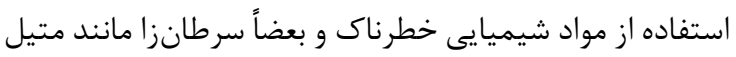

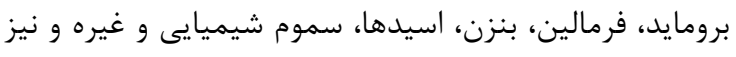

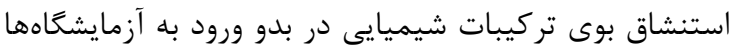

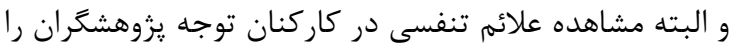

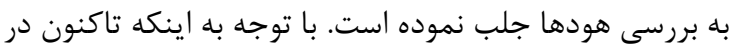

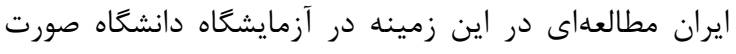

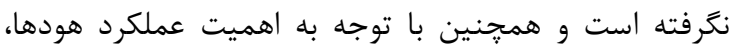

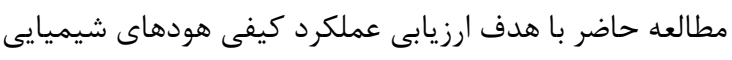

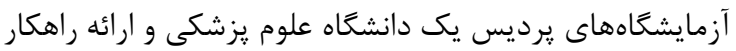

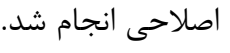

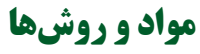

بلمنظور ارزيابى عملكرد هودهاى مستقر در آزمايشكاه هاى

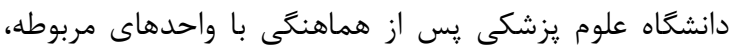

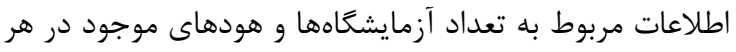

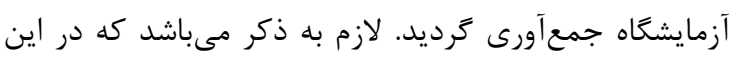

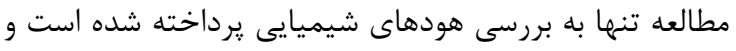

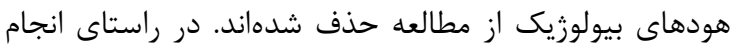

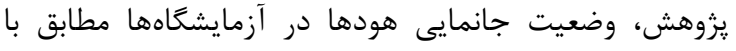

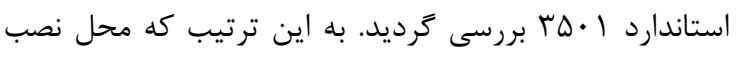

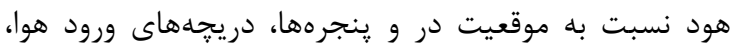

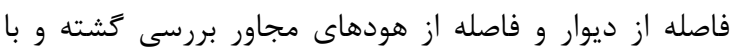

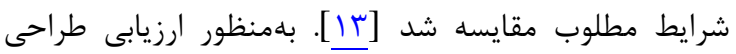

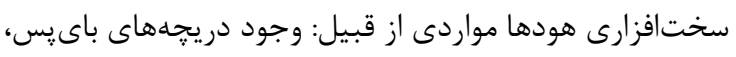

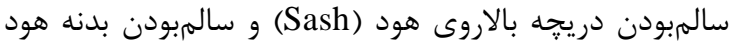

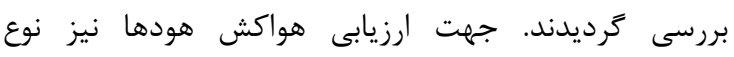

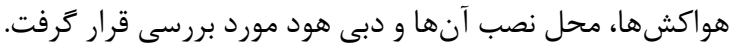

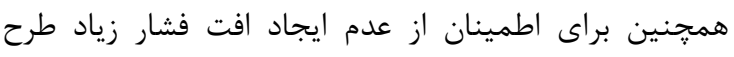

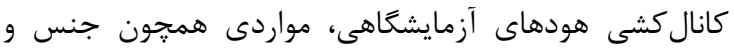

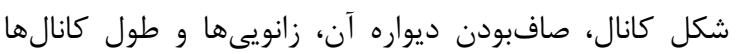

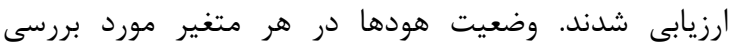

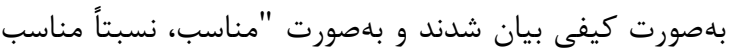

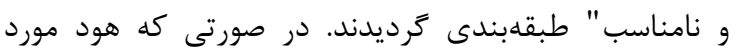

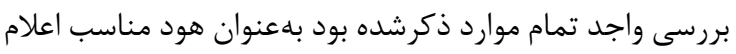

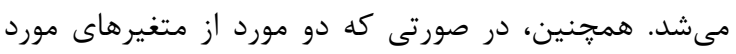

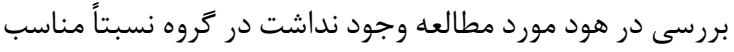

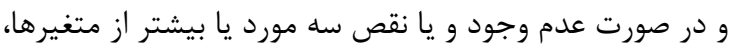

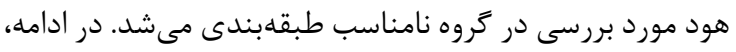
مطابق با آزمونهاى كيفى توصيهشده در استاندارد معتبر شامل:
شيميايى در اين آزمايشكاهها ضرورت دارد؛ اما نكته قابل توجه

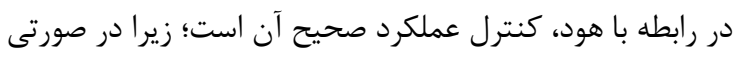

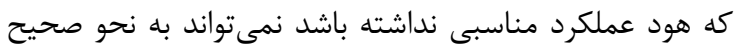

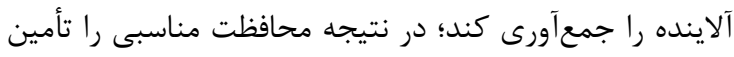

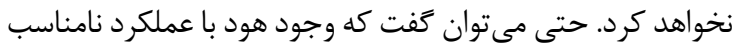

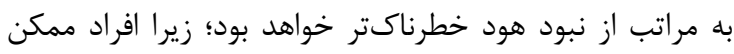

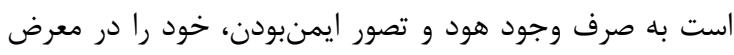

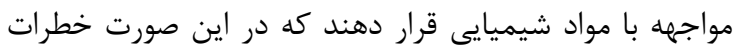

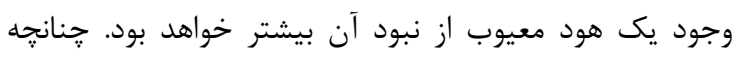

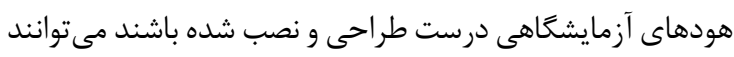

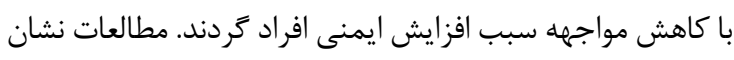

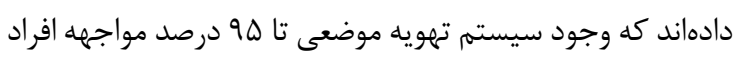

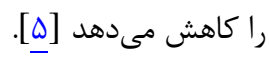
كاهى ممكن است با رسيدن غلظت تركيبات آلاينده به إنها

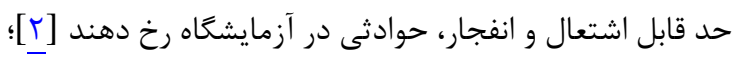

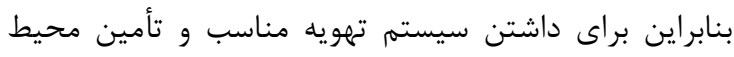

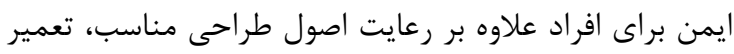

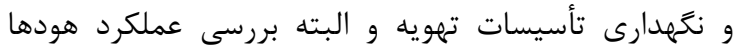

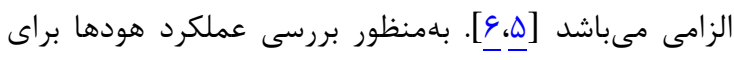

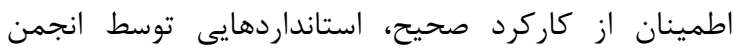

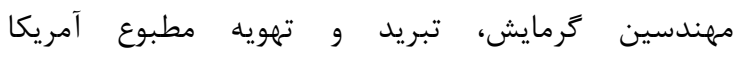
ASHRAE: American Society of Heating, ) (Refrigerating and Air-conditioning Engineers تدوين و توصيه شده است. روشهاى بررسى مطابق با استاندارد

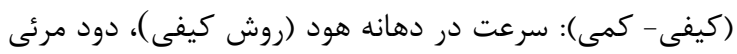

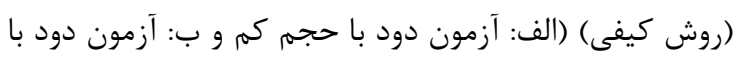

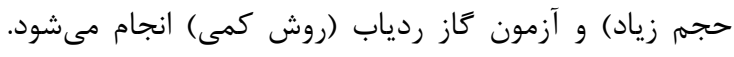

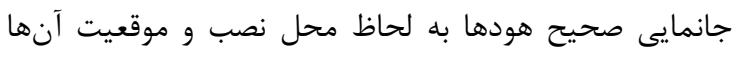

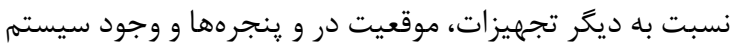

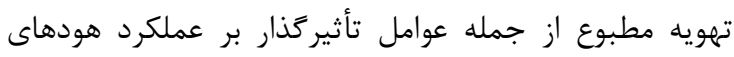

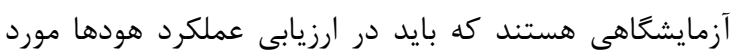

توجه قرار كيرند [V] در اين راستا، مطالعاتى در ارتباط با ارزيابى سيستمهاى

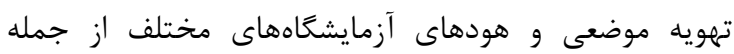

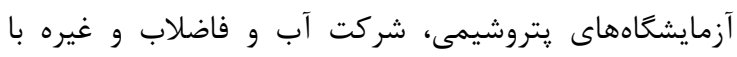

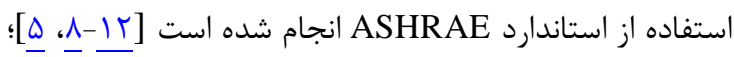

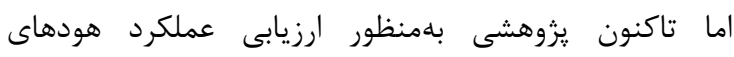

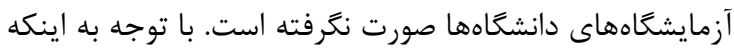

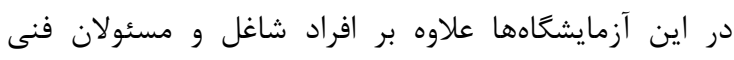

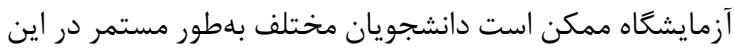

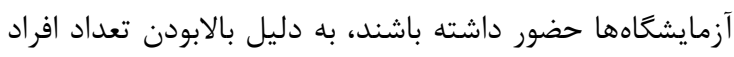
در معرض مواجهه، اين امر نيازمند توجه بيشتر است. شايان

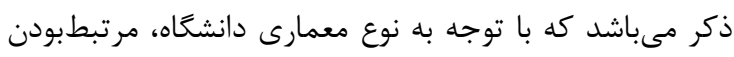




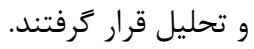

\section{بافته.}

در اين مطالعه بأ هود شيميايى در آزمايشخاههاى

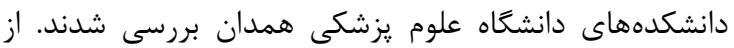

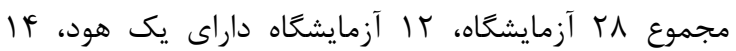

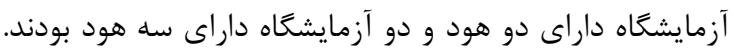

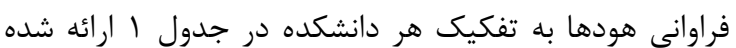

وضعيت سختافزارى و فنى هودها در جدول r ذكر شده

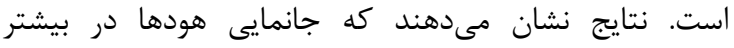

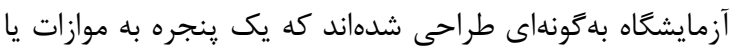

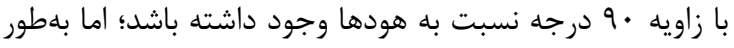
عمده فاصله هودها از سيستمهاى تهويه مطبوع به ميزان قابل نـان

$$
\text { قبول و در حد ه/ر متر يا بيشتر بود. }
$$

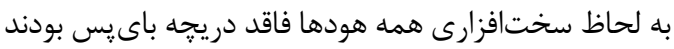
و در برخى از هودها دريجه بالارو به سختى قابل تنظيم بوده

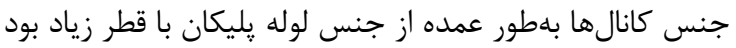

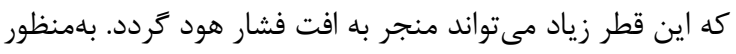

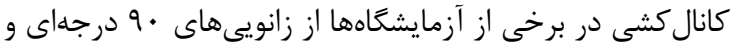

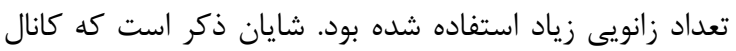

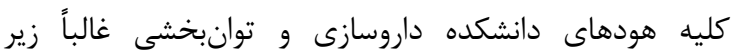
يارتيشنهاى سقفى به شكل توكار استفاده شده و بهطور كامل

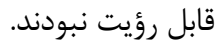

در برخى از آزمايشخاهها مشاهده شد كه از هواكش محورى ند

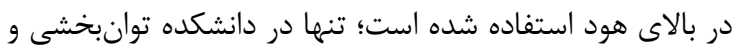

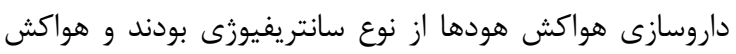

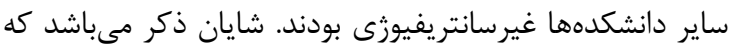

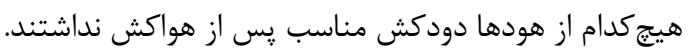

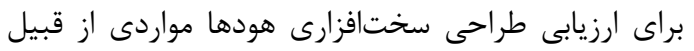

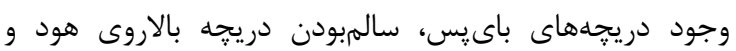
سالمبودن بدنه هود بررسى گرديد. ذكر اين نكته ضرورت دارد كه در آزمايشعاه ياتولوزى اصلاً

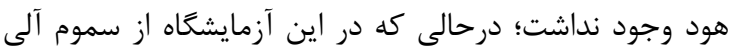
كلره و فسفره استفاده مى كرديد.
آزمون سرعت دهانه هود، آزمون اثر جريان متقاطع و آزمون

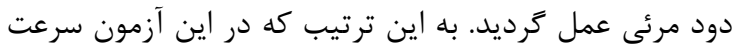

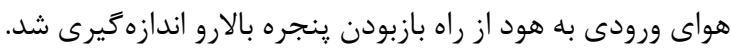

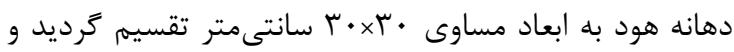

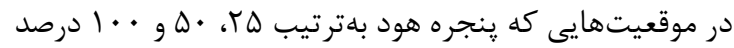

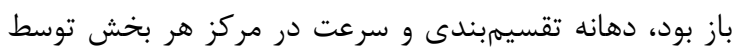

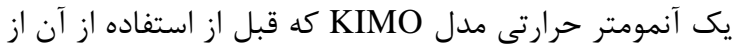

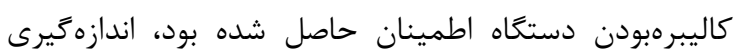
گشت. براى هودهايى با مساحت دهانه بزرگتر، دهانه باز هود

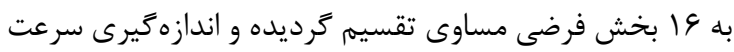

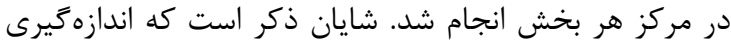

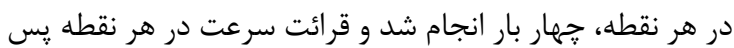

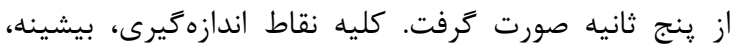

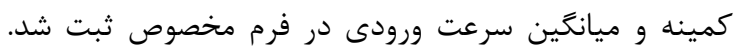

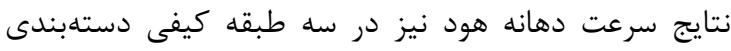

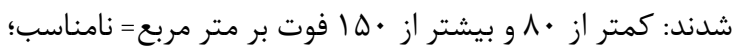

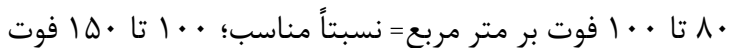
بر متر مربع= مناسب.

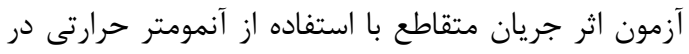

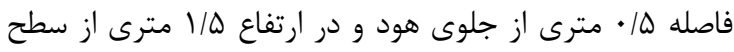

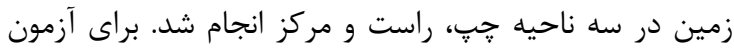

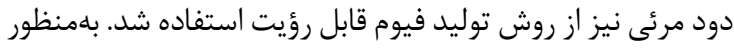

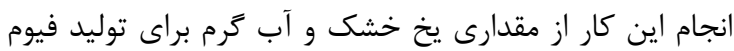
قابل رؤيت و مرئىسازى جريان هواى داخل هود استفاده گرديد مرديد

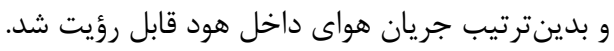
بلمنظور اطمينان از عدم ايجاد آشفتكى، توقف، جرئ هريان

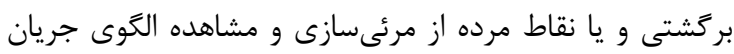

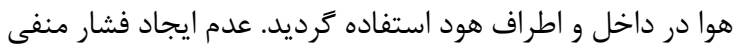
در فضاى نصب هود و بركشت آلاينده به داخل محيط آزمايشعاه

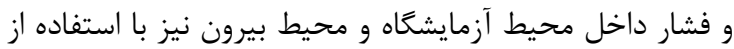

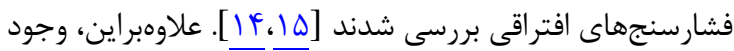

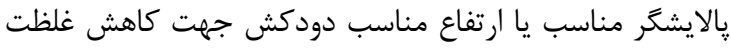

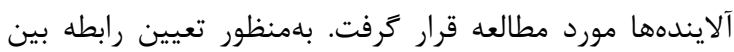

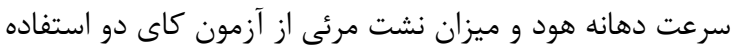

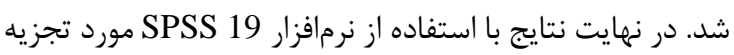

جدول ا: فراوانى آزمايشعاهها و هودها به تفكيك دانشكدهها

\begin{tabular}{|c|c|c|c|c|}
\hline \multicolumn{2}{|c|}{ هودها } & \multirow{2}{*}{ آزمايشگاهها } & \multirow{2}{*}{ دانشكده } & \multirow{2}{*}{ رديف } \\
\hline درصد & فراوانى & & & \\
\hline $19, \pi$ & V & f & بهداشت & 1 \\
\hline$r, r$ & 1 & 1 & پير إيزشكى & r \\
\hline$r \cdot, q$ & 9 & $\wedge$ & يزشكى & r \\
\hline v & r & r & توانبخشى & r \\
\hline$\Delta r, \Delta$ & r & IT & داروسازى & $\Delta$ \\
\hline $1 \cdots$ & F & rA & & جمع كل \\
\hline
\end{tabular}


باز بود و تجهيزاتى داخل هود وجود نداشت، حداقل سرعت دهانه

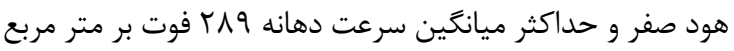

$$
\text { بود (جدول س). }
$$

همانطور كه در شكل I نشان داده شده است، با توجه به

طبقهبندى كيفى انجامشده براى سرعت دهانه هود، نتايج بيانكر

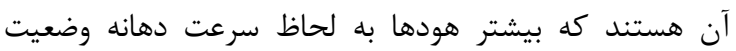

نامناسبى دارند.

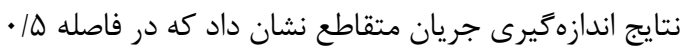

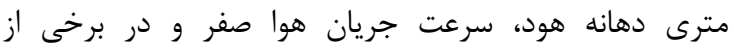

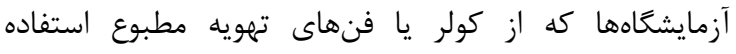

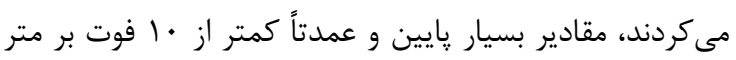

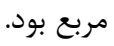

علاوهبراين، يافتهها حاكى از آن بودند كه A/Aها درصد از
بايد عنوان نمودكه در آزمايشعاههاى فيزيولوزى و و فماد

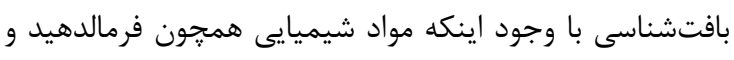

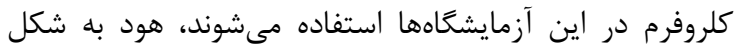

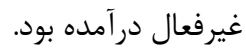
فشار داخل آزمايشگاه در همه آزمايشكاههاى مورد برد بردى

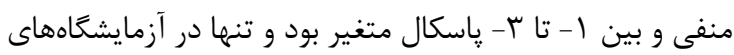
حيوان خانه، انكلشناسى و قارجشناسى آناسئ اختلاف فشار بين محيط داخل آزمايشگاه و بيرون آن وجود نداشت آنسان.

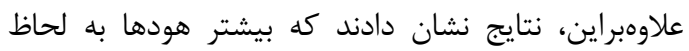

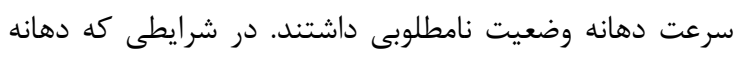

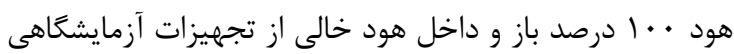

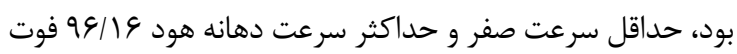

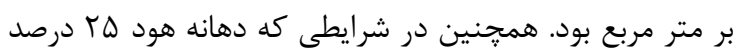

جدول r: وضعيت مشخصات فنى هودهاى مستقر در آزمايشگاههاى مورد مطالعه

\begin{tabular}{|c|c|c|c|}
\hline \multicolumn{3}{|c|}{ وضعيت هود (درصد) } & \multirow{2}{*}{ مشخصات هود } \\
\hline نامناسب & نسبتاً مناسب & مناسب & \\
\hline ז/ اله درصد & F/N/A درصد & • • درصد & سختافزار هود \\
\hline F F & ه/ ب درصد & س/ ا درصد & جانمايى هود \\
\hline & & F/V & كانال كشى هود \\
\hline 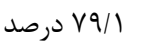 & |/ إ درصد & س/ץ درصد & هواكش \\
\hline
\end{tabular}

جدول ץ: ميانگين، حداقل و حداكثر سرعت دهانه هود در مساحت هاى مختلف دهانه باز هود

\begin{tabular}{|c|c|c|c|c|}
\hline حداكثر (fpm) & 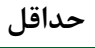 & ميانغين و انحراف معيار (fpm) & وجود تجهيزات در زير هود & 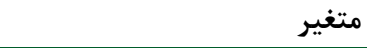 \\
\hline 94 & . & $\mid \kappa r / l \cdot \pm r r / \Lambda q$ & 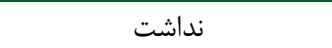 & \multirow{2}{*}{ سرعت دهانه در حالت . . ا درصد } \\
\hline $94 / 19$ & • & $F Y / T \cdot \pm Y Y / / D$ & 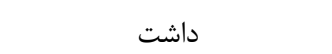 & \\
\hline $10 \cdot / 91$ & $\cdot$ & $\vee r / \wedge q \pm r \Delta / \mathcal{c}$. & ن & \multirow{2}{*}{ سرعت دهانه در حالت •ه درصد } \\
\hline $1 \Delta F$ & . & $V I / \Delta V \pm T Y / V H$ & داشت & \\
\hline rrq/VD & · & $I T \cdot / r \cdot \pm \Delta \Lambda / r \Lambda$ & 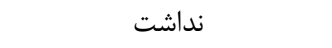 & \multirow{2}{*}{ سرعت دهانه در حالت هT درصد } \\
\hline r८9 & . & ITY/VTEST/AT & 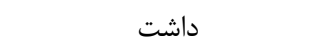 & \\
\hline
\end{tabular}

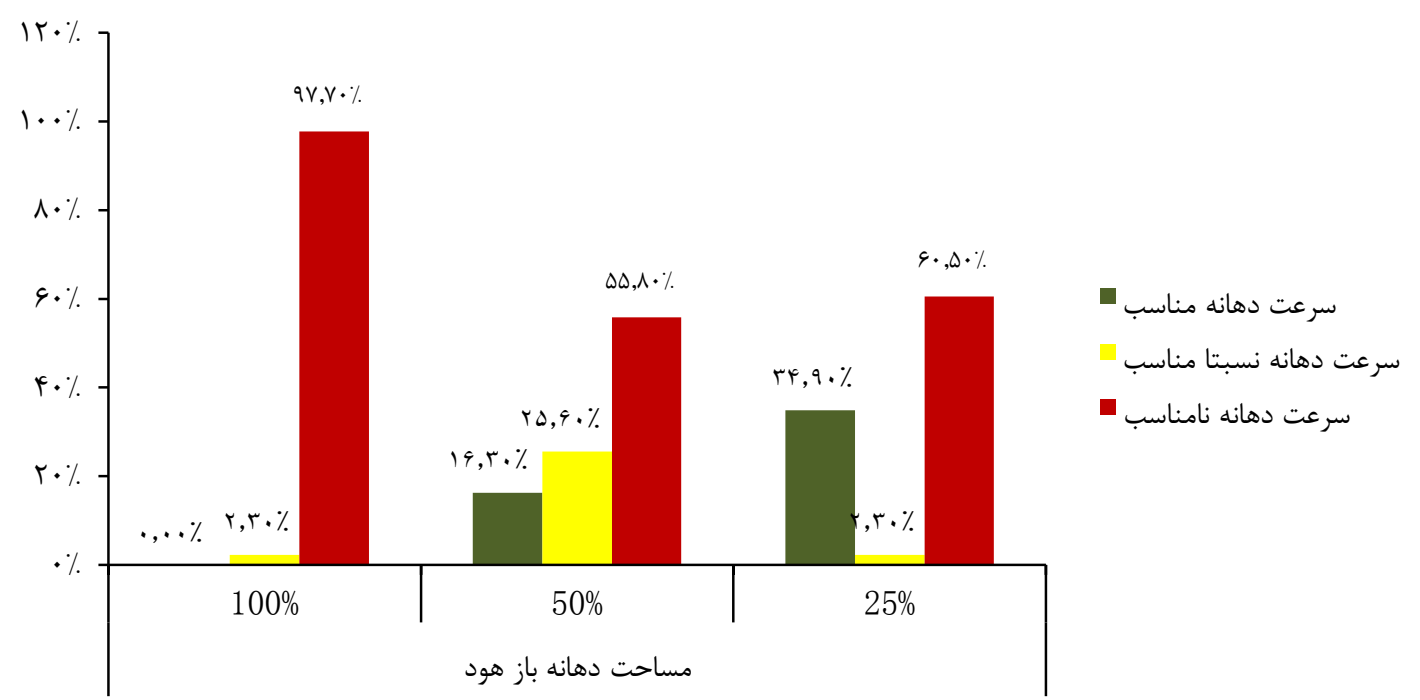

شكل ا: وضعيت سرعت دهانه در سه حالت مساحت باز دهانه هود 
هود، نشتى قابل رؤيت افزايش داشت. در مطالعه جعفرى و

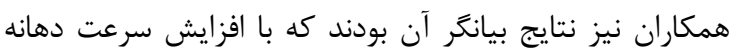

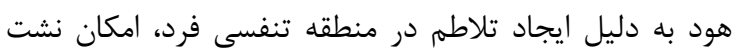

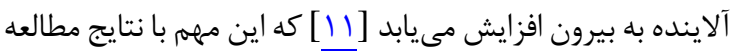
حاضر همخوانى دارد. در مطالعه حاضر در همه آزمايشكاههاى مورد برد بررسى فشار

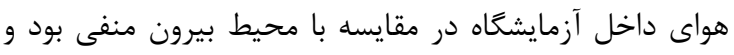

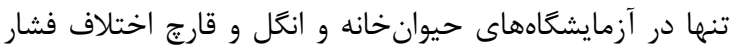

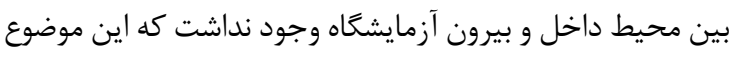

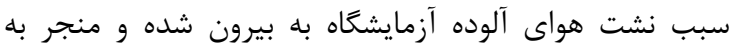

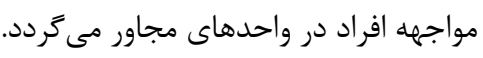

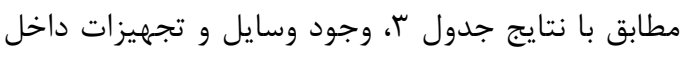
هود موجب شده است تا ميانگين سرعت دهانه هود كمتر

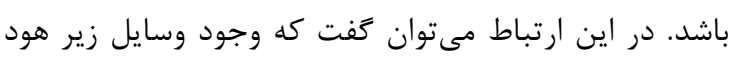

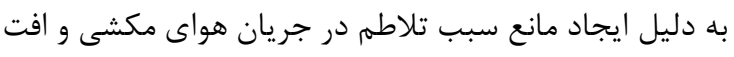

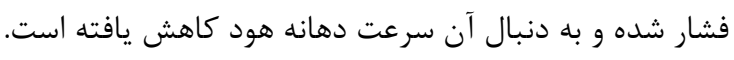

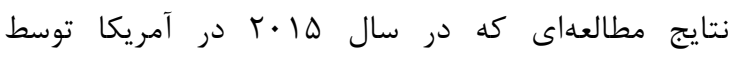

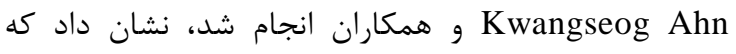
بهممريختهبودن هود به لحاظ آمارى تأثير معنادارى ندارد؛ امان

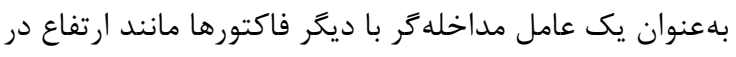

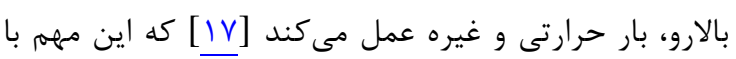
نتايج مطالعه حاضر همخوانى دارد.

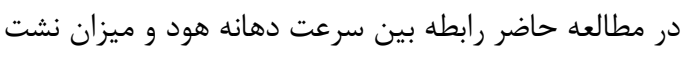
قابل رؤيت كه يس از مرئىسازى جريان هوا انجام شد، معنادار

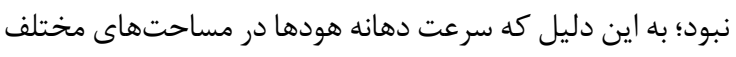

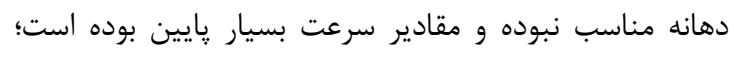

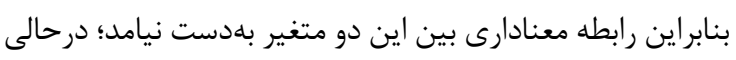

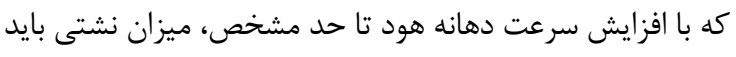

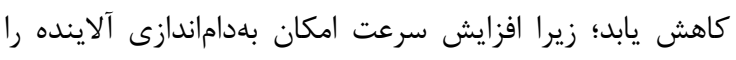

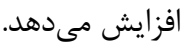
از سوى ديخر، در مطالعه حاضر كمترين سرعت دهانه هود

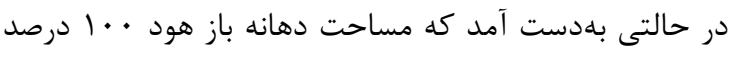

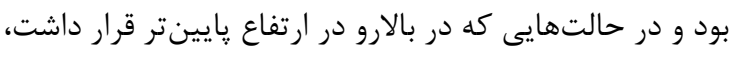

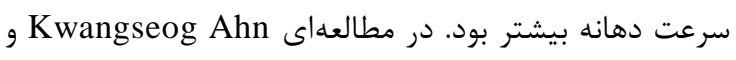

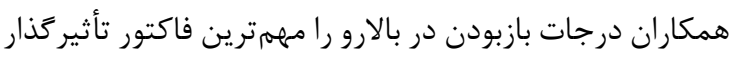

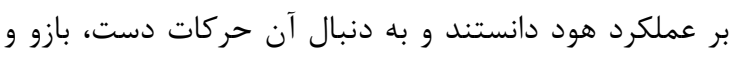
تنه كاربر و بار حرارتى را فاكتورهاى مهلهم و مؤثر قلمداد كردند.

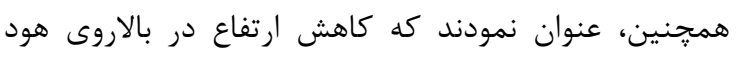

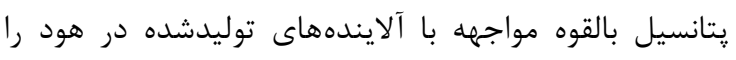

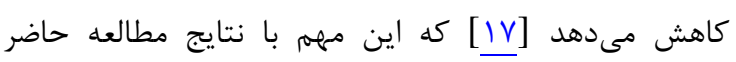
مطابقت دارد. از جمله محدوديتهاى اين مطالعه طراحى نامناسب هودها

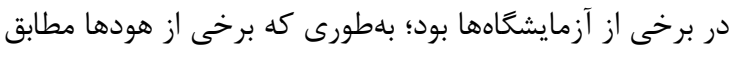

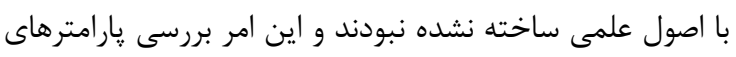

هودها نشتى قابل رؤيت نداشتند و r/ • ه درصد داراى نشتى قابل

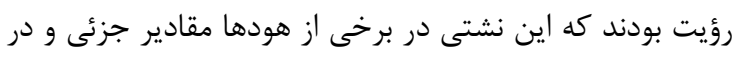

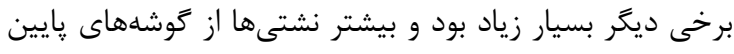

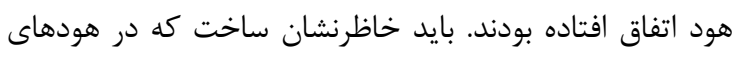

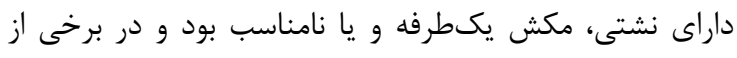

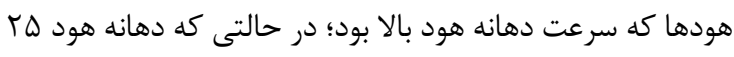

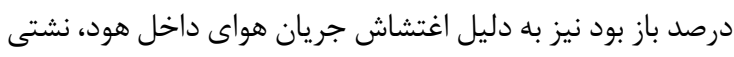
قابل رؤيت افزايش داشت.

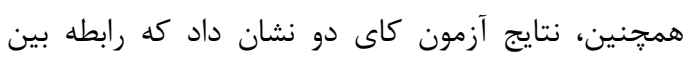

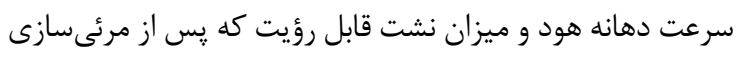

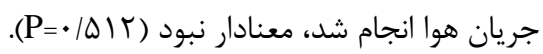

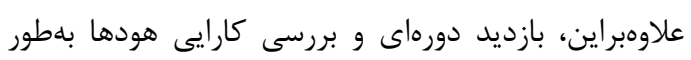

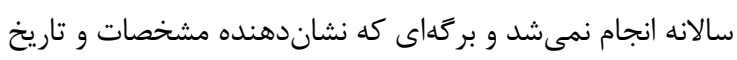
آخرين بازرسى هودها باشد وجود نداشت.

در اين مطالعه بهمنظور ارزيابى عملكرد هودها، سرعت

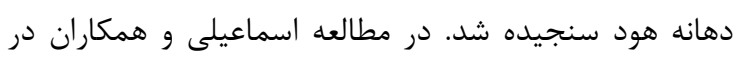

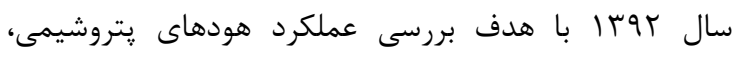
اندازهزيرى سرعت دهانه بهعنوان يك روش مطمئن جهت

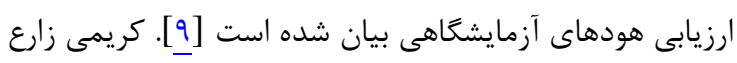

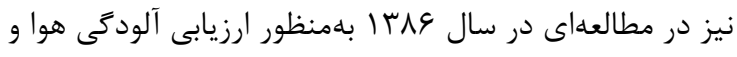

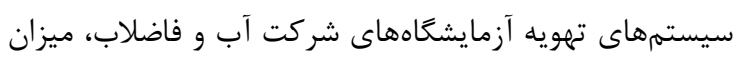

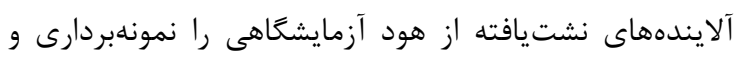

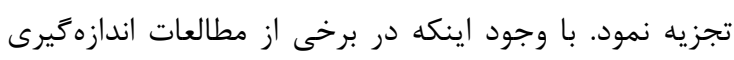

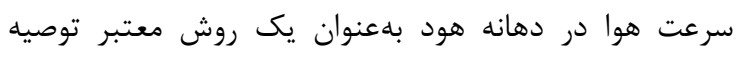

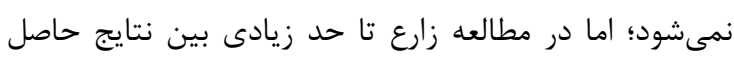

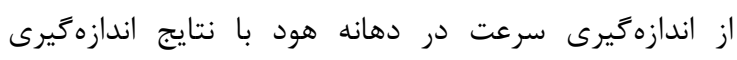
آلايندههاى هوا همخوانى وجود داشت [ـ [1].

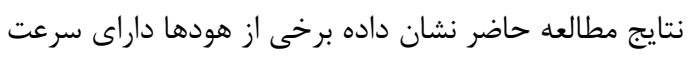

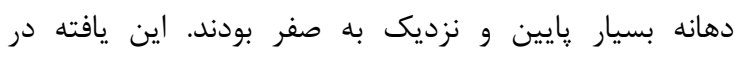

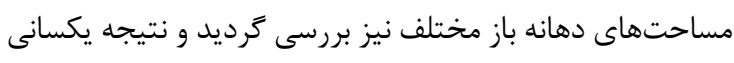

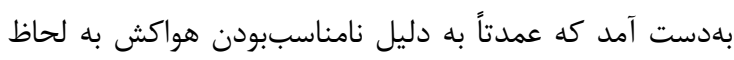

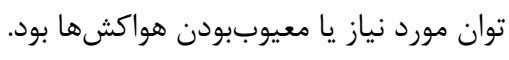

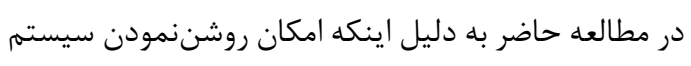

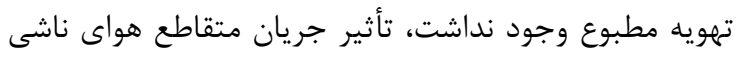

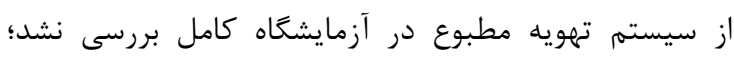

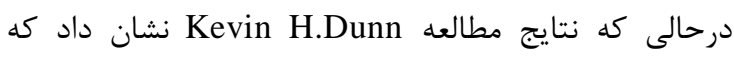

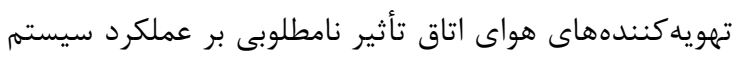

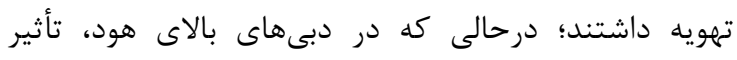

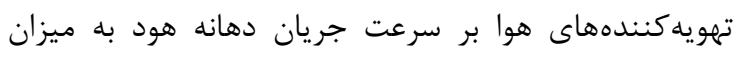
حداقل بود [1] در هودهايى كه سرعت دهانه بالا بود، زمانى كه فا د درصد از دهانه هود باز بوده است به دليل اغتشاش جريان هوائ دهان بالادي دمانى داخل 


$$
\begin{aligned}
& \text { توسط افراد متخصص صورت كيرد و آموزشهاى لازم براى }
\end{aligned}
$$

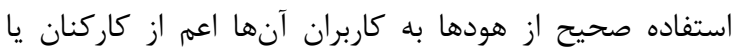

$$
\begin{aligned}
& \text { دانشجويان ارائه كردد. }
\end{aligned}
$$

$$
\begin{aligned}
& \text { تشكر و قروراذى } \\
& \text { بدينوسيله نويسندگان مراتب تشكر و قدردانى خود را از }
\end{aligned}
$$

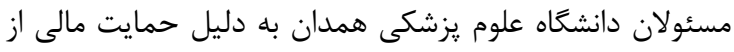

$$
\begin{aligned}
& \text { اين مطالعه كه در قالب طرح :يزوهشى دانشجويى با شماره عاره }
\end{aligned}
$$

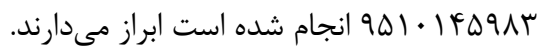

\section{REFERENCES}

1. Malakouti J, Rezazade Azari M, Goneh Farahani A. Occupational exposure risk assessment of researchers to harmful chemical agents. Med J Mil Med. 2010;13(3-4):31-5. [Persian]

2. Olin GR. The hazards of a chemical laboratory environment-a study of the mortality in two cohorts of Swedish chemists. Am Ind Hyg Assoc J. 1987;39(7):557-62. PMID: 567938 DOI: 10.1080/0002889778507808

3. Malakouti J, Jang S, Mosaferchi S, Haseli F, Azizi F, Mahdinia M. Health risk assessment of occupational exposure to hazardous chemicals in laboratories of Qom University of Medical Sciences. Iran Occupat Health. 2014;11(2):13-25. [Persian]

4. Abbas M, Zakaria AM, Balkhyour MA, Kashif M. Chemical safety in academic laboratories: an exploratory factor analysis of safe work practices $\&$ facilities in a university. $J$ Saf Stud. 2016;2(1):1-4.

5. Nor MR. Effectiveness of local exhaust ventilation systems in reducing personal exposure. J Appl Sci. 2014;14(13):1365. DOI: $10.3923 /$ jas.2014.1365.1371

6. Marlow DA, Looney T, Reutman S. An evaluation of local exhaust ventilation systems for controlling hazardous exposures in nail salons. Division of Applied Research and Technology Engineering and Physical Hazards Branch EPHB Report; 2012.

7. American Society of Heating. Refrigerating and airconditioning engineers. Atlanta: Method of Testing Performance of Laboratory Fume Hoods; 1985.

8. Ahmadpour A, Jahan Fathi K. Performance evaluation central laboratory hoods special zone petrochemical research and technology company. First National Conference on Health, Safety \& Environment (HSE), Islamic Azad University of Mahshahr, Mahshahr; 2011.

9. Arezoo E, Farideh G, Soodabeh Z. Qualitative assessment of local ventilation in petrochemical company laboratories for reducing staffs exposure. J Occupat Health Engin.

$$
\text { مورد نظر را با مشكل مواجه مىساخت. }
$$

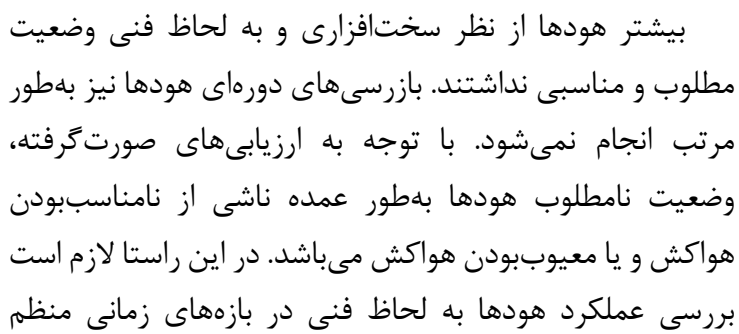

2014;1(3):60-6. [Persian]

10. Karimizare A. Evaluation of air pollution and ventilation systems exist in Tehran water and waste water co. laboratories and design of effective ventilation systems. Research and Science UNI, Islamic Azad University, Tehran; 2007-2008. [Persian]

11. Jafari MJ, Kalantari S, Zendehdel R, Sarbakhsh P. The possibility of applying less tracer gas in ASHRAE-110-95 method of hood performance test. Saf Promot Injury Prev. 2013;1(3):160-7. [Persian]

12. Mari Oriyad H, Zare Derisi F, Jahangiri M, Rismanchian M, Karimi A. Evaluation of heating, ventilation, and air conditioning (HVAC) system performance in an administrative building in Tehran (Iran). Health Saf Work. 2014;4(3):59-66. [Persian]

13. Laboratory self-inspection checklist. University of Manitoba. Available at: URL: http://www.umanitoba.ca/admin/ human_resources/ehso/media/CLIPInspectChecklistDec06 .pdf; 2016.

14. Diberardinis LJ. American national standard for laboratory ventilation. New York: American Industrial Hygiene Association; 1993.

15. Halid MH. A study on the performance of local exhaust ventilation system using Mahalanobis approach. [Doctoral Dissertation]. Malaysia: University Malaysia Pahang; 2013.

16. Dunn KH, Tsai CS, Woskie SR, Bennett JS, Garcia A, Ellenbecker MJ. Evaluation of leakage from fume hoods using tracer gas, tracer nanoparticles and nanopowder handling test methodologies. $J$ Occup Environ Hyg. 2014;11(10):D164-73. DOI: 10.1080/15459624.2014. $\underline{933959}$

17. Ahn K, Ellenbecker MJ, Woskie SR, DiBerardinis LJ. Effects of work practices and upper body movements on the performance of a laboratory fume hood. J Chem Health Saf. 2016;23(6):2-9. DOI: 10.1016/j.jchas.2015.10.022 